\title{
Editorial:
}

\section{A special issue to mark the 90th Anniversary of College of Life Sciences, Zhejiang University}

Jin-rong PENG ${ }^{\dagger 1}$, Kun-liang GUAN ${ }^{2}$, De-yuan $\mathrm{HONG}^{3}$, Xin-hua $\mathrm{LIN}^{4}$, Huan-ming YANG ${ }^{5}$, Yu-xian $\mathrm{ZHU}^{6}$

${ }^{1}$ College of Animal Sciences, Zhejiang University, Hangzhou 310058, China

${ }^{2}$ Department of Pharmacology and Moores Cancer Center, University of California, San Diego, La Jolla, CA 92093, USA

${ }^{3}$ State Key Laboratory of Systematic and Evolutionary Botany, Institute of Botany, Chinese Academy of Sciences, Beijing 100093, China

${ }^{4}$ State Key Laboratory of Genetic Engineering, School of Life Sciences, Zhongshan Hospital, Fudan University, Shanghai 200438, China

${ }^{5}$ Beijing Genomics Institute-Shenzhen, Shenzhen 518083, China

${ }^{6}$ Institute for Advanced Studies, Wuhan University, Wuhan 430072,

China

†E-mail: pengjr@zju.edu.cn

https://doi.org/10.1631/jzus.B1910002

The College of Life Sciences (CLS) remains one of the most prestigious - and the oldest - colleges in Zhejiang University. This special issue, which includes 16 reviews contributed by our alumni and faculties, is dedicated to mark the 90th Anniversary of CLS. The reviews provide a glimpse of current progresses in the areas of life sciences such as biochemical processes and their association with diseases (Ding et al., 2019; Hu et al., 2019; Jin et al., 2019; Nie and Yi, 2019), cancer biology (Feng, 2019; Huang et al., 2019; Leonard and Zhang, 2019; Zhu F et al., 2019), plant and environmental microbiology ( $\mathrm{Li}$ et al., 2019; Yang et al., 2019; Zhu XR et al., 2019), cell cycle (Gao and Liu, 2019; Zhang et al., 2019), RNA biology (Gudenas et al., 2019; Luo et al., 2019), and protein structural biology (Yang and Tang, 2019).

CLS, formerly known as the Department of Biology, National Zhejiang University-founded in September 1929-is proud of its 90-year history, during which it has built a tradition of excellence in

(D) ORCID: Jin-rong PENG, https://orcid.org/0000-0002-0793-4848 (C) Zhejiang University and Springer-Verlag GmbH Germany, part of Springer Nature 2019 education, research, and service. To date, the college has produced more than 5380 undergraduates and 2930 graduates. Our alumni have been making important contributions to not only science but also our society. Many distinguished biologists, including Shi-zhang BEI, Zong-luo LUO, Zhao-qian ZHANG, Jia-zhen TAN (C. C. TAN), Lv-ji SHI, Ren-bao ZHU, Zhen YAO, and Jiao-nai SHI, were students or faculty of this institution.

CLS was established in 1999 after Zhejiang Agriculture University, Hangzhou University, and Zhejiang Medical University were merged with Zhejiang University in 1998. At present, the college has about 120 faculty and staff members, including 45 professors and 27 associate professors, some of whom have been awarded by the Chinese government's Thousand Talents Program, the Chinese Ministry of Education's Cheung Kong Scholars Program, and the Zhejiang Provincial Hundred Talents Program. Furthermore, at present, 927 full-time students are registered with the college for various programs, including undergraduate studies, masters program, and doctoral studies.

The college includes four departments: Department of Ecology, Department of Biological Science, Department of Biotechnology, and Department of Bioinformatics, which provide students with distinctive education and training in life sciences. Recognizing the college's achievements in life sciences education, the Ministry of Education in China considers CLS as one of the National Teaching Bases for Biological Sciences and Biotechnology. Undergraduates are required to complete four years of study and research training to obtain their BS degree. The major courses include General Biology, Biochemistry, Cell Biology, Genetics, Molecular Biology, Microbiology, Animal or Plant Physiology, and Bioinformatics. A series of elective courses that reflect the frontiers in biological sciences and technology, such as Bioengineering, 
Neurobiology, Immunology, and Developmental Biology, were also available. All undergraduate students are encouraged to join a laboratory for research training after completing two years of course study.

The college has three State Key DisciplinesEcology, Botany, and Biophysics-and two Provincial Key Disciplines-Genetics and Microbiology. It also includes the State Key Laboratory of Plant Physiology and Biochemistry, the State Conservation Center for Gene Resources of Endangered Wildlife, the Key Laboratory of Biosystem Homeostasis and Protection of the Ministry of Education, and the Provincial Key Laboratory of Cell and Genetic Engineering. The college receives research funds from the National Natural Science Foundation of China, the Ministry of Science and Technology of China, and the local governments and enterprises. The annual research budget of the college is around 80 million CNY, and the annual publications in Science Citation Indexed (SCI) journals are over 160. Numerous scientific articles authored by the students and faculty of CLS have been published in leading international journals, including Nature, Science, PNAS, Circulation Research, Cell Research, Nature Communications, Plant Cell, PLoS Genetics, Molecular Cell, ISME, and Ecology. The excellent research groups at CLS have revealed many important genes involved in plant nutrition, specific mechanisms in RNA splicing, and molecular mechanisms of pathogenesis triggered by microorganisms. Our faculties have also developed ecological approaches to protect panda and crested ibis and devised strategies for rice-fish co-cultivation and urban ecology protection.

The progress achieved by CLS would not have been possible without the committed efforts of all its members, including our staff, students, and alumni. With devotion in our hearts and scientific spirit in our minds, CLS strives to evolve and excel. We are committed to the highest level of education and research excellence in the area of life sciences and hope that you will enjoy reading the articles in this special issue.

\section{References}

Ding HY, Xie YN, Dong Q, et al., 2019. Roles of hyaluronan in cardiovascular and nervous system disorders. $J$ Zhejiang Univ-Sci B (Biomed \& Biotechnol), 20(5):428-436. https://doi.org/10.1631/jzus.B1900155

Feng GS, 2019. Tumor immunology and immunotherapy: a journey I started from Hangzhou. J Zhejiang Univ-Sci B (Biomed \& Biotechnol), 20(5):373-380.
https://doi.org/10.1631/jzus.B1900204

Gao SW, Liu F, 2019. Novel insights into cell cycle regulation of cell fate determination. J Zhejiang Univ-Sci B (Biomed \& Biotechnol), 20(6):467-475. https://doi.org/10.1631/jzus.B1900197

Gudenas BL, Wang J, Kuang SZ, et al., 2019. Genomic data mining for functional annotation of human long noncoding RNAs. J Zhejiang Univ-Sci B (Biomed \& Biotechnol), 20(6):476-487. https://doi.org/10.1631/jzus.B1900162

Hu SY, Zhuang QQ, Qiu Y, et al., 2019. Cell models and drug discovery for mitochondrial diseases. J Zhejiang Univ-Sci B (Biomed \& Biotechnol), 20(5):449-456. https://doi.org/10.1631/jzus.B1900196

Huang FT, Sun J, Zhang L, et al., 2019. Role of SIRT1 in hematologic malignancies. J Zhejiang Univ-Sci B (Biomed \& Biotechnol), 20(5):391-398. https://doi.org/10.1631/jzus.B1900148

Jin LH, Fang ZP, Fan MJ, et al., 2019. Bile-ology: from bench to bedside. J Zhejiang Univ-Sci B (Biomed \& Biotechnol), 20(5):414-427. https://doi.org/10.1631/jzus.B1900158

Leonard M, Zhang X, 2019. Estrogen receptor coactivator Mediator Subunit 1 (MED1) as a tissue-specific therapeutic target in breast cancer. $J$ Zhejiang Univ-Sci B (Biomed \& Biotechnol), 20(5):381-390. https://doi.org/10.1631/jzus.B1900163

Li HH, Wang YT, Wang Y, et al., 2019. Bacterial degradation of anthraquinone dyes. J Zhejiang Univ-Sci B (Biomed \& Biotechnol), 20(6):528-540. https://doi.org/10.1631/jzus.B1900165

Luo J, Xiong Y, Fu PF, et al., 2019. Exosomal long non-coding RNAs: biological properties and therapeutic potential in cancer treatment. J Zhejiang Univ-Sci B (Biomed \& Biotechnol), 20(6):488-495. https://doi.org/10.1631/jzus.B1900039

Nie H, Yi W, 2019. O-GlcNAcylation, a sweet link to the pathology of diseases. J Zhejiang Univ-Sci B (Biomed \& Biotechnol), 20(5):437-448. https://doi.org/10.1631/jzus.B1900150

Yang JL, Fan W, Zheng SJ, 2019. Mechanisms and regulation of aluminum-induced secretion of organic acid anions from plant roots. J Zhejiang Univ-Sci B (Biomed \& Biotechnol), 20(6):513-527. https://doi.org/10.1631/jzus.B1900188

Yang QF, Tang C, 2019. On the necessity of an integrative approach to understand protein structural dynamics. $J$ Zhejiang Univ-Sci B (Biomed \& Biotechnol), 20(6):496-502. https://doi.org/10.1631/jzus.B1900135

Zhu F, Zhang W, Yang T, et al., 2019. Complex roles of necroptosis in cancer. J Zhejiang Univ-Sci B (Biomed \& Biotechnol), 20(5):399-413. https://doi.org/10.1631/jzus.B1900160

Zhu XR, Wang H, Sun J, et al., 2019. Pericarp and seed of litchi and longan fruits: constituent, extraction, bioactive activity, and potential utilization. J Zhejiang Univ-Sci B (Biomed \& Biotechnol), 20(6):503-512. https://doi.org/10.1631/jzus.B1900161

Zhang YX, Pan WY, Chen J, 2019. p53 and its isoforms in DNA double-stranded break repair. J Zhejiang Univ-Sci B (Biomed \& Biotechnol), 20(6):457-466. https://doi.org/10.1631/jzus.B1900167 